\title{
The African Languages Research Institute: A Milestone in the Development of the Zimbabwean Languages*
}

Emmanuel Chabata, African Languages Research Institute (ALRI), University of Zimbabwe, Harare, Zimbabwe (emmanuelchabata@yahoo.com)

\begin{abstract}
This article is an assessment of the work the African Languages Research Institute (ALRI) has done towards developing the indigenous languages of Zimbabwe. It looks at what the research team at ALRI has achieved, first in initiating serious research on the Zimbabwean languages and the progress it has made towards achieving its goal, developing and raising the status of these languages. It also considers what ALRI has planned for the future of the different categories or levels into which the various Zimbabwean languages have been classified. Part of the assessment focuses on measures ALRI has put in place to ensure the initiated research programme is sustainable and will continue in future. The article furthermore discusses the importance of the research work being done at ALRI, especially with regard to language development as a means towards self-realisation and -actualisation, national advancement and the sustenance of the languages involved. ALRI's agenda is also analysed to see how well it agrees with popular thinking in Zimbabwe concerning the development and promotion of all of the indigenous languages.
\end{abstract}

Keywords: ALRI, CAPACITY BUILDING, INSTITUTIONALISATION, LANGUAGE HARMONISATION, LANGUAGE STANDARDISATION, MONOLINGUAL LEXICOGRAPHY, ZIMBABWEAN LANGUAGES

Opsomming: Die African Languages Research Institute: 'n Mylpaal in die ontwikkeling van die Zimbabwiese tale. Hierdie artikel is 'n evaluering van die werk wat die African Languages Research Institute (ALRI) gedoen het in die ontwikkeling van die inheemse tale van Zimbabwe. Dit kyk na wat die navorsingspan bereik het, eerstens deur ernstige navorsing oor die Zimbabwiese tale te onderneem en die vordering wat gemaak is met die bereiking van sy doel, die ontwikkeling en die statusverhoging van hierdie tale. Dit beskou ook wat ALRI beplan het vir die toekoms van die verskillende kategorieë of vlakke waarin die onderskeie Zimbabwiese tale geklassifiseer is. 'n Deel van die evaluering fokus op maatreëls wat ALRI in plek gestel het om te verseker dat die onderneemde navorsingsprogram volhoubaar is en in die toekoms sal voortgaan. Verder bespreek die artikel die belangrikheid van die navorsingswerk wat by ALRI gedoen word, veral met betrekking tot taalontwikkeling as 'n manier tot selfverwesenliking en -aktualisering,

* This article is based on a paper presented at the Sixth International Conference of the African Association for Lexicography organised by the Sesotho sa Leboa National Lexicography Unit, University of the North (at present University of Limpopo), Polokwane, Republic of South Africa, 8-10 July 2001. 
nasionale vooruitgang en die onderhoubaarheid van die betrokke tale. ALRI se agenda word ook ontleed om te sien hoe goed dit ooreenstem met die algemene denke in Zimbabwe betreffende die ontwikkeling en bevordering van al die inheemse tale.

Sleutelwoorde: ALRI, VERMOËNSBOU, INSTITUSIONALISERING, TAALHARMONIERING, TAALSTANDAARDISERING, EENTALIGE LEKSIKOGRAFIE, ZIMBABWIESE TALE

\section{Introduction}

In this article, which focuses on the contribution of the African Languages Research Institute (ALRI) towards the development of Zimbabwe's indigenous languages, language development is viewed as involving two steps. The first is that of reducing a language to writing, the aim being that of standardising it to become a literary language. In this case, the standardisation process results in the establishment of an alphabet for the language and the rules of spelling and word division to be followed when writing that language. The rules are generally referred to as the language's orthography. The second step, which follows after the establishment of a language's orthography, is the development of tools that further enhance the research on and documentation of a particular language. Some such tools include general and specialised dictionaries, corpora, morphological parsers, syntactic analysers and spell checkers, the compilation of which rely on the agreed or standard orthography of a language. In the light of what is involved in these two steps, it becomes clear that language development is an ongoing process of researching and updating a language's orthography and its descriptive tools. Once a standard orthography has been developed and the language has been adequately described and documented, its status is automatically raised. In this article, it will be considered how ALRI is trying to raise the status of Zimbabwean indigenous languages through its research agenda.

To date, efforts towards developing the African languages spoken in Zimbabwe are more than a century old. Researchers, both foreign and local, as individuals or small groups, have made varying contributions towards the standardisation and documentation of the country's different languages. The earliest efforts comprised missionary activities, which mainly centred on the development of orthographies for various languages and/or dialect clusters. This was realised through different missionary groups strategically located in different parts of the country where they set up presses for printing Bibles, church literature and educational books to create literature for their new converts. Although missionary efforts have often been viewed as aimed at creating a literate group of individuals to use in spreading the gospel, the local languages ended up gaining in the process by having their orthographies developed. Examples where missionary activities benefited local languages can be drawn from developments in Shona, Kalanga and Nambya. For Shona, for example, missionary activities based in different parts of Mashonaland led to 
the creation of dialect clusters, identified as Zezuru, Karanga, Manyika, Ndau and Korekore. The missionaries working on these particular dialect clusters were then instrumental in developing orthographies for each of them. However, after the establishment of a central colonial government and also following the general problems of writing differently in rather highly mutually intelligible dialects, a standard Shona orthography was created through the recommendations of Doke (1931) in his Report on the Unification of the Shona Dialects. Since then, the Shona writing system is largely based on these recommendations. Doke's writing system was successful because all the background research and necessary documentation had been done by missionaries, who had championed the idea of promoting literary Shona. It was also the missionaries who gave the necessary personal and financial assistance to Doke. Similar missionary efforts were witnessed at Inyati mission in Plumtree, which led to the development of a writing system for Kalanga. A writing system for Nambya again resulted from efforts by the Catholic missionaries based at St Mary's mission in Hwange.

Following the establishment of writing systems in the different languages through missionary activities, researches on Zimbabwe's indigenous languages, by individuals and groups of linguists and non-linguists flourished. Basic grammar books were produced, especially for Shona and Ndebele which had been selected as the indigenous languages to be taught in schools in Mashonaland and Matebeleland respectively (see Doke 1931). Bilingual dictionaries were also published (see, for example, Hannan 1959, Dale 1981, and Moreno 1988, among others). Whilst all these efforts should be acknowledged for pioneering the research on and documentation of the various indigenous languages, they were either limited in scope or lacked the much needed focus towards the development and raising of the status of these languages. For example, most of the work on documenting the indigenous languages ensued from research by individuals towards the attainment of their academic qualifications at Honours, Masters and Doctoral levels. Whilst these are valued works, they tended to be narrowly focused on specific linguistic aspects which lacked the necessary impact or influence needed in the formulation of national policies to be followed in the development and raising the status of the Zimbabwean languages. As has also been observed, the dictionaries published were bilingual. Generally speaking, bilingual dictionaries are mainly meant for second-language speakers. In the case of the Zimbabwean languages, the dictionaries were compiled for the use of the colonial authorities. Such dictionaries do not effect as direct an influence on language development as monolingual dictionaries, neither do they contribute to empower the concerned languages.

Language researches carried out before the establishment of ALRI were not coordinated. The studies tended to narrowly focus on one language or dialect or another and also to be based on short-term research programmes. However, most language researchers in Zimbabwe, just as in other countries of the world, have now realised that their efforts can bear more fruit if they are coor- 
dinated at local, regional, national and even international levels. They have also realised that through such coordination larger and long-term research programmes can be embarked on in a more sustainable manner. Such a coordination of research programmes for the Zimbabwean languages has come with the establishment of ALRI.

\section{What is ALRI?}

ALRI is a non-faculty, interdisciplinary research unit based at the University of Zimbabwe, and is dedicated to the development of all indigenous languages spoken in Zimbabwe. Its goals are contained in its mission statement, which is to research, document and develop the Zimbabwean indigenous languages in order to promote and expand their use in all spheres of life. Formerly the

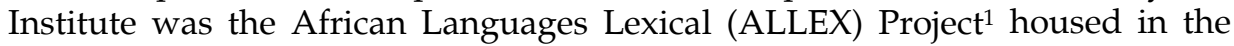
Department of African Languages and Literature at the University of Zimbabwe. The ALLEX Project, which was launched in 1992, had the compilation of a variety of general and specialised monolingual dictionaries in Zimbabwe's two national languages, Shona and Ndebele, as its main goal. Thus, the work of the ALLEX Project (1992-2000) has culminated in the publication of two general medium-sized Shona monolingual dictionaries, Duramazwi reChiShona (DRC) (Chimhundu 1996) and Duramazwi Guru reChiShona (DGC) (Chimhundu 2001) as well as a general medium-sized Ndebele monolingual dictionary, Isichazamazwi SesiNdebele (ISN) (Hadebe 2001). It has also seen the building and maintenance of fairly large corpora for Shona and Ndebele which have since been used to aid the process of compiling the ALLEX dictionaries. The successful dictionary making has also allowed for work to be commenced on the development of other language research tools such as morphological parsers and syntactic analysers for the two languages.

ALRI was established in 2000, transforming the ALLEX Project into a permanent research unit. As noted in Chimhundu (2005: 2), the decision to create ALRI resulted from the intention to institutionalise the experimental work done by the ALLEX Project so that the scope of its research agenda could be expanded and broadened to include more local languages. The success the Project had achieved in its experimental research on and documentation of Shona and Ndebele was taken as a model in the programmes for the other local languages.

\section{ALRI's research activities}

As a means towards achieving its goals of developing and raising the status of the country's languages, ALRI has embarked on a number of research activities with each activity aimed at a particular aspect of language development. The next sections will discuss some of the activities with which the ALRI research teams have commenced. These are described under the following subheadings. 


\subsection{Language standardisation}

As already noted, standardisation is the first step towards the development of any language. It is only when standardised that a language can further be developed so as to be able to function in all spheres of life. It is also when a language has been standardised that it can be used as an efficient communicative tool in, for instance, education, government, industry, commerce and law. It is because of its importance that ALRI has put the standardisation of all of Zimbabwe's languages at the core of its research agenda. In Zimbabwe, some languages already have standard orthographies while others have no writing systems at all. Because of this, ALRI has defined its role as twofold. With regard to those languages not yet standardised, its role is that of developing common writing systems for them. The bulk of the languages without standard orthographies are the country's 'minority' or community languages, examples of which include, among others, Shangani, Tonga, Sotho, Chewa, Tswawo and Venda. The planned work at ALRI is such that once standard writing systems have been developed for these languages, basic grammars can then be written. Subsequently, it would become possible also to teach these languages as subjects in schools. The languages can further be developed through modernisation.

With regard to languages already having orthographies, the standardisation process will be advanced by the revision and refinement of the existing orthographies as well as the writing of new and the updating of existing grammars, basing decisions on new knowledge gained from new research methods. For example, research advances so far made in Shona corpus-assisted lexicography have shown the need for the inclusion into the Shona alphabet of letters and clusters not acceptable in the current Shona orthography. Some such letters and clusters include $l, t h, m l$ and $d h l$. The letter $l$, which is often introduced into the language through borrowed words from English, has, for example, been discarded from the Shona orthography on the assumption that wherever it is encountered in borrowed words, it will consistently be replaced by $r$. However, corpus research has shown the increased use of this letter by Shona speakers in their daily lives, hence the need to revise the current Shona orthography in order to include the $l$. The same can be said of the th cluster which had also been discarded on the assumption that it would be replaced in Shona by the letter $t$. In Ndebele, the increased use of the letter $r$, which is not part of the current Ndebele orthography, has also necessitated the need for revising Ndebele's orthography to make the inclusion of $r$ possible.

\subsection{Monolingual lexicography}

As already intimated, the major objective of both the ALLEX Project and ALRI is to develop tools enhancing research on and the development of the indigenous languages of Zimbabwe. Such tools include monolingual dictionaries, 
whose importance in language standardisation and documentation need not be over-emphasised. They play an important role in developing a language for it to be used in all aspects of life. For example, their compilation usually leads to the development of terminology employed in specialised fields, which later becomes the basis for expanding the language concerned. The reason for this is that dictionaries, especially monolingual dictionaries, have a standard-setting influence since they are generally used by language speakers as their main tools in interpreting the rules about the spelling, meaning and pronunciation of words.

Monolingual lexicography only started with the ALLEX Project under whose leadership, funding and guidance the publication of the first-ever monolingual dictionaries in Shona and Ndebele have been made possible. The production of general and specialised monolingual dictionaries has had a positive impact on the process of raising the status of Shona and Ndebele. Mention of a few Shona monolingual dictionaries published or being compiled under the ALLEX/ALRI research programme would suffice as illustrative examples of how monolingual lexicography has led to the recognition of Shona as a language that can be used in any sphere of life, including specialised areas. To start with, the publication of DRC and DGC had some impact on the general public and professionals in different specialised fields. The result was that professionals from various fields approached ALRI for collaborative research aimed at compiling dictionaries, glossaries and other reference works for their respective fields of expertise. One such work that resulted from this collaborative research is a small-to-medium sized monolingual dictionary of Shona biomedical terms, Duramazwi reUrapi neUtano (Mpofu et al. 2004), which was a product of a collaborative research venture between researchers from ALRI and others from the Institute of Continuing Health Education (ICHE). Other similar research projects currently under way include one on a dictionary of Mathematics terms and another on a dictionary of Physics terms, both of which are being carried out by researchers at ALRI in collaboration with specialists in the respective fields of study. These are projects the respective specialists brought to ALRI for assistance, and are being carried out in addition to what ALRI itself had planned. Other projects still at the planning stage include one for a dictionary of agricultural terms and another for a dictionary of geographical terms. This kind of response is evidence of the extent of the influence ALRI's work has had on the Zimbabwean society at large.

Other ALRI projects pertaining to terminological dictionaries include the Shona dictionary of musical terms, Duramazwi reMimhanzi (Mheta et al. 2005). Also completed are two specialised dictionaries, the Ndebele dictionary of musical terms Isichazamazwi SezoMculo (Nkomo and Moyo 2006) and the Shona dictionary of linguistic and literary terms Duramazwi reDudziramutauro neUvaranomwe (Chimhundu and Chabata 2007). Work is also under way on, among others, the revised and enlarged Ndebele dictionary. Planned work at ALRI furthermore include monolingual lexicographical projects in Zimbabwe's 
minority languages, starting with those that have been prioritised by both ALRI and the Ministry of Education, that is, Kalanga, Nambya, Shangani and Tonga. Through general and terminological dictionaries, technical terms for different specialist fields are collected or coined and recorded in systematic ways helpful to speakers or users of a particular language. The availability and standardisation of these terms through monolingual dictionaries will eventually make it possible to use the indigenous languages as communicative tools in all aspects of life. This will, in turn, raise their status for it would become possible for them to be used in important areas such as education, government, industry, commerce and law.

Monolingual dictionaries are also compiled as a logical step towards language modernisation. With the help of decisions based on language descriptions contained in monolingual Shona and Ndebele dictionaries, morphological parsers, syntactic analysers and spell checkers are being developed for Shona and Ndebele. These research tools make automatic language analysis possible.

\subsection{Corpora building and maintenance}

A corpus has been defined by Renouf (1987: 1) as 'a collection of texts, of the written or spoken word, which is stored and processed on computer for the purposes of linguistic research'. According to this description, it implies an electronic or machine-readable body of texts. Reference is made to a corpus stored in the computer from which words, phrases and sentences or even chunks of text can easily be retrieved. The importance of electronic corpora as valuable sources of evidence for linguistic and other language related analyses need not be over-emphasised. As observed by Kennedy (1998: 88), for example, a linguistic corpus, in whatever form, is important as a basis for more accurate and reliable descriptions of how languages are structured and used. Corpora are very important tools in providing conclusive evidence for researches in fields such as lexicography, dialectology, semantics, syntax, psycholinguistics, phonology, sociolinguistics, code-switching and code-mixing. These are disciplines whose focus is on the manner of how language is either structured or used, or in which evidence for any controversial issues can only come from instances where language is found in use. It is because of the importance of this resource that ALRI has made the building and maintenance of corpora in the various indigenous Zimbabwean languages one of its priority research activities. This is especially important because the research done by ALRI is based not only on theoretical linguistics, but also on linguistic data showing how speakers use language. The aim is to publish reference works, which reflect and represent actual, not theoretically possible language usage.

To date, fairly large corpora have been compiled for Shona ${ }^{2}$ and Ndebele, the two main indigenous languages of Zimbabwe. The materials for the corpora come from both transcribed oral interviews on various aspects of life and written literature of various kinds, which are later encoded or scanned, tagged 
and parsed before they are stored as text and sound in electronic form. In addition, there is also an image corpus being built for the benefit of dictionaries that would need illustrative examples in the form of pictures. The images are drawn and stored in a database for future use when required. Work on building corpora in some of the country's minority languages have since started, with serious work already commenced on Kalanga, Nambya, Tonga and Shangani. The corpora in these community languages are modelled according to the standards adopted in the building of the Shona and Ndebele corpora. Although the ALRI corpora are primarily constructed for lexicographic use, they have been found to be more and more useful in other language and language-related studies already identified above as dialectology, semantics, syntax, psycholinguistics, phonology, sociolinguistics, code-switching and code-mixing. In these studies, text corpora, for example, are important in providing contexts, both linguistic and cultural, in which words and phrases are used. This is especially possible since part of the corpora comprise texts from oral interviews taken from naturally occurring language in use by mother-tongue speakers of the respective languages. Currently, ALRI text corpora, which are also accessible to international researchers on the Internet, are being exploited for various language and language-related activities the world over. For example, the Shona, Ndebele and Nambya corpora are extensively used by Zimbabwean researchers studying abroad as well as at institutions in other parts of Africa.

\subsection{Language harmonisation}

Language relatedness is one of the fascinating aspects of any linguistic study. In the case of Africa and Zimbabwe, most indigenous languages are generally related by sharing the same morphological, phonological and syntactic systems. Unfortunately the history of colonisation has led to the creation of artificial boundaries between these otherwise highly related language varieties. The missionaries and colonial administrators who established programmes for the development of orthographies for indigenous languages deliberately ignored the similarities between language varieties and decided to develop divergent orthographies even for mutually highly intelligible varieties. As noted by Simango (2003: 33), the use of diverse orthographies for mutually intelligible language varieties is detrimental to the development of the concerned languages for two basic reasons. Firstly, it reduces the level of mutual intelligibility, through the written word, among language varieties that were and still remain mutually intelligible in their spoken forms. For example, it makes it very difficult for communities who use diverse orthographies to share information conveyed via the written medium. Secondly, divergent orthographies tend to distort the ground-level realities by exaggerating the differences existing among language varieties, at the same time obscuring their similarities. Sadly for Zimbabwe, this historical fact has also led to the elevation of some dialects to the status of independent languages and in the process entrenching 
divisions among groups of people who were previously and who can still easily be united by the same language.

Because of the disadvantages of using diverging orthographies for mutually intelligible language varieties, research efforts in Sub-Saharan Africa are now concentrated on harmonising the orthographies for related languages. There has been a realisation that people can be better served if orthographies are harmonised in such a way that the written forms reflect the similarities existing between varieties of each language cluster. In Zimbabwe, such a programme will be realised through efforts by ALRI. Language harmonisation has been considered important for ALRI with the realisation that the bulk of Zimbabwe's language varieties (which have since been officially recognised as independent languages and have had different orthographies developed for them) are mutually highly intelligible in speech. Despite the fact that different orthographies have been designed for them, Shona, Kalanga and Nambya, for example, are to such an extent mutually intelligible that speakers from the three languages can easily communicate with very few difficulties. It is because of this high mutual intelligibility that Kalanga has often been described as one of the Shona dialects, and also that Nambya is sometimes regarded a subdialect of Kalanga. ALRI's philosophy behind harmonising such related languages is that it will foster greater unity amongst linguistically related peoples. This is also hoped to widen readership and markets for written materials. In other words, it will become easier and cheaper to produce one document that can be circulated widely than to reproduce the same document in many different orthographies of languages otherwise closely related.

ALRI's planned harmonisation programme will be at two levels. Firstly, it will try to harmonise related language clusters. For example, attempts will be made to design a common orthography for Eastern Shona (Shona spoken in the eastern parts of Zimbabwe and Mozambique), Central Shona (which is spoken in many parts of Zimbabwe) and Western Shona (spoken in the western parts of Zimbabwe and Botswana and generally referred to as Kalanga). Secondly, the programme will see the harmonisation of languages Zimbabwe shares with its neighbours defined as separate languages only on the basis of national boundaries, but otherwise having high mutual intelligibility. Examples of language clusters in need of harmonisation include South African and Zimbabwean Ndebele, Mozambican and Zimbabwean Shona, Botswanan and Zimbabwean Kalanga, Zambian and Zimbabwean Tonga and Zimbabwean, Mozambican and South African Shangani.

\section{Strategies for development}

All the different research activities discussed above are aimed at developing Zimbabwean languages for use in all aspects of life and also at modernising them in the process. However, the activities can only be carried out successfully within the framework of a well-designed and sustained research programme. It is in this spirit that ALRI has adopted a number of strategies con- 
sidered necessary for undertaking a sustained research programme. In this section, a few of these strategies will be discussed.

\subsection{Institutionalisation}

One of the strategies adopted by ALRI is the institutionalisation of the work initiated by the ALLEX Project through the creation of a permanent research institute. With the realisation that the ALLEX Project will, like any other project, have a life after which it would be concluded, institutionalisation was seen as a way of ensuring long-term planning. Institutionalisation would mean much for the sustained development of Zimbabwean languages. Firstly, institutionalisation entailed that lexicography and the other research activities initiated under the ALLEX Project would become permanent activities without a time limit. Secondly, it also meant that the responsibility of supporting the research agenda would become national and local. This kind of support lasts longer when compared to donor-funded programmes only continuing for the period donors are willing to provide support. As fields like lexicography and corpora building are multidisciplinary, unnecessary constraints are placed on any such activity housed within a department with its own needs and goals which guide its development as a discipline. The transformation from a project within a department to an autonomous research unit has, for example, made it possible and relatively easy for researchers at ALRI to organise collaborative projects with researchers from other institutions and other fields of study.

\subsection{Capacity building}

It has already been noted that research on Zimbabwean languages has had a long history. However, the greatest part of this history has been dominated by individual researchers who often were non mother-tongue speakers of the respective languages, and who also tended to work on short-term research projects. For example, it has already been observed that research on the country's indigenous languages started with missionaries who studied and documented the languages and dialects for evangelising purposes. In most of these projects, mother-tongue speakers of respective languages were only valuable as research informants or assistants during the data collection stage. The speakers of the different languages were not trained to become experts in linguistic research. What this entailed was that at the end of each programme no mothertongue speakers of the respective languages were equipped with the knowledge of continuing with or improving on the work initiated. This is rather different from the approach adopted at ALRI where great emphasis has been laid on capacity building. From the outset, a training component has been built into the ALLEX/ALRI programme. Through its training programme, members of the Institute, who are all mother-tongue speakers of one or another of Zim- 
babwe's indigenous languages, are trained in all aspects of research activities taking place at the Institute. Researchers in Shona and Ndebele, who received their training and experience from their research collaborators from Scandinavia through the ALLEX Project, have had the responsibility of training other speakers of these and other Zimbabwean languages in lexicographic and other language-related activities such as corpus building and maintenance, dialectology and others. The idea is that these speakers, once trained, would spearhead the research and documentation of their respective languages. This entails that the undertaking of documenting and developing Zimbabwean languages will not end with ALRI, but will be continued.

The pool of necessary expertise is being created through two kinds of training. There is the element of formal academic training at Honours, Masters and Doctoral levels through the provision of scholarships to members to study in the fields of linguistics and lexicography. One of the requirements for taking up the scholarships is that the recipients would develop their dissertations or theses around some linguistic or lexicographic aspect of their mother-tongues. This requirement is meant especially to initiate research on and documentation of the country's minority languages. The idea is to move away from the missionary approach of involving mother-tongue speakers only as research informants, cultivating a sense of ownership of the research agenda amongst mother-tongue participants. This approach has been adopted for two basic reasons. Firstly, it lays the foundation for sustained development. Secondly, researchers at ALRI cannot accomplish all the required work on all of the country's languages by themselves. Because of this, there is a need to train mothertongue speakers of different languages who are expected to contribute substantially towards research programmes in their respective language communities. In such cases, ALRI's role would only become advisory and supervisory.

Training has also taken the form of practical on-the-job training, especially with regard to new computational language research methods. This kind of training is done through annual workshops organised for members. These have been highly successful as practical training for various IT linguistic and lexicographic tasks and also for project planning, budgeting and management. Through linkage with other institutions of higher learning which have a language component, capacity building has been extended even to non-ALRI staff members, the idea being that expanding the capacity building programme would create a culture of collaborative research, which ensures sustainability of quality research at national level.

\subsection{Community involvement}

Any kind of research involving humans needs the community, which is both the object of study and the principal beneficiary of the results. For the research programme at ALRI, community involvement is an indispensable component. Apart from providing the much needed moral and logistical support and the 
required data, the community is also the consumer of ALRI's products. The idea, therefore, is that the community should understand and also be actively involved in the research programme. In this way, the community is afforded an opportunity to decide what is of immediate importance to them; thus also participating in determining the course the research programme should follow. Only when this is achieved, the programme can be appreciated, supported and also be assured of success and continuity.

Since its inception ALRI has made its research agenda known to the Zimbabwean community through its various activities. Some such activities include its outreach programmes, which over the years have been carried out in all the districts across the country. During these programmes, those with an interest in language research are brought together to have formal and informal discussions with researchers from ALRI and to make their contributions towards the research agenda. The community has also been engaged in the Institute's field researches. Because of this, the Zimbabwean community now feels part of the ALLEX/ALRI research programme, showing its willingness to actively participate in the research activities initiated by the Institute.

\subsection{Collaborative research}

Unlike the preceding research programmes which were either conducted by individuals or small groups of researchers aimed at investigating a particular aspect of language, ALRI's programme is much bigger, incorporating specialists in different but relevant fields of study. It is a collaborative research programme involving computer scientists, lexicographers, linguists, teachers, the community of speakers and other relevant stakeholders. For example, specialised dictionary projects carried out so far have seen the active involvement of and representation from all universities and teachers' colleges which offer training in the African languages of Zimbabwe, and some education officers and university students acting as research assistants during data collection and other fieldwork activities.

In the research programmes carried out before, ALRI has also tended to compartmentalise some languages by treating them as if they were only spoken in Zimbabwe. Researches on cross-border languages, for example, have not recognised the fact that these languages are also being studied in neighbouring countries. With regard to such languages, the programme at ALRI will see a collaborative approach involving researchers and research institutes from neighbouring countries co-operating for the common goal of developing the languages concerned. This means that research on Kalanga, for example, will involve researchers from Zimbabwe and Botswana, Shangani researchers from Zimbabwe, South Africa and Mozambique, and Tonga Zimbabwean and Zambian researchers. A collaborative research has two advantages. Firstly, scholars from different institutions and countries will be afforded a chance to share research ideas, experiences and findings. Secondly, research costs are also shared. This sharing of human and financial resources naturally leads to a fruit- 
ful programme where quality results are achieved quickly and cheaply. Such research links have already been initiated and logistics are currently being worked out for collaborative research to commence.

\section{Conclusion}

In this article, a description has been given of the work ALRI is doing towards developing and raising the status of the indigenous languages of Zimbabwe. Some of the strategies ALRI has put in place as measures of ensuring that its research programme is sustained in future have also been discussed. The discussion also aimed to highlight some of the reasons why the status of Zimbabwe's indigenous languages could not be raised despite the fact that research on them has had a long history. However, the success ALRI has achieved in cultivating a love for the indigenous languages has been shown as evidence for the use of its monolingual dictionaries by people who traditionally tended to look down upon these languages.

\section{Notes}

1. Currently, the ALLEX Project which receives the bulk of its funding from NUFU, the Norwegian Programme for Development, Research and Education, is the main project being undertaken at ALRI. Through this project, Zimbabwean scholars obtained training in computational lexicography and in corpora building and maintenance from their counterparts in Norway and Sweden through collaborative research, mainly with scholars and/or researchers at the Universities of Oslo (Norway) and Gothenburg (Sweden).

2. For detailed discussions on how the Shona corpus, for example, was compiled, refer to Chabata (2000) and Mberi (2002).

\section{References}

Chabata, E. 2000. The Shona Corpus and the Problem of Tagging. Lexikos 10: 75-85.

Chimhundu, H. (Ed.). 1996. Duramazwi reChiShona. Harare: College Press.

Chimhundu, H. (Ed.). 2001. Duramazwi Guru reChiShona. Harare: College Press.

Chimhundu, H. 2005. Lexicography and Language Raising: Dictionaries in Zimbabwean Languages. Public lecture presented as part of the Golden Jubilee Celebrations of the University of Zimbabwe, Harare, 13 April 2005.

Chimhundu, H. and E. Chabata (Eds.). 2007. Duramazwi reDudziramutauro neUvaranomwe. Gweru: Mambo Press.

Dale, D. 1981. Duramazwi: A Basic Shona-English Dictionary. Gweru: Mambo Press.

Doke, C.M. 1931. Report on the Unification of the Shona Dialects Carried Out under the Auspices of the Government of Southern Rhodesia and the Carnegie Corporation. Hertford: Stephen Austin.

Hadebe, S. (Ed.). 2001. Isichazamazwi SesiNdebele. Harare: College Press.

Hannan, M. 1959. Standard Shona Dictionary. Salisbury: The College Press. 
Kennedy, G. 1998. An Introduction to Corpus Linguistics. London/New York: Longman.

Mberi, N.E. 2002. The Categorical Status and Functions of Auxiliaries in Shona. Unpublished D.Phil. Thesis. Harare: University of Zimbabwe.

Mheta, G. et al. (Eds.). 2005. Duramazwi reMimhanzi. Gweru: Mambo Press.

Moreno, A. 1988. Nambya Dictionary. Gweru: Mambo Press.

Mpofu, N. et al. 2004. Duramazwi reUrapi neUtano. Gweru: Mambo Press.

Nkomo, D. and N. Moyo (Eds.). 2006. Isichazamazwi SezoMculo. Gweru: Mambo Press.

Renouf, A. 1987. Corpus Development. Sinclair, J.M. (Ed.). 1987. Looking Up: An Account of the COBUILD Project in Lexical Computing and the Development of the Collins COBUILD English Language Dictionary: 1-40. London: Collins.

Simango, S.R. 2003. Do We Dare Harmonise Orthographies? Chebanne, A. et al. (Eds.). Unifying Southern African Languages: Harmonisation and Standardisation. 2003. Cape Town: Centre for Advanced Studies of African Society (CASAS). 